Contemporary Issue

ANNUAL HEALTH INCIDENCE

\author{
Col DS GOEL*
}

\begin{abstract}
The 'Report on the Health of the Armed Forces' and the 'Annual Report on the Health of the Army' are documents that contain very useful information. There is, however, a surprising lack of awareness about the data contained within and hence a total absence of critical comment. The average length of stay in respect of certain illnesses, even those like common cold, showed wide disparity between various groups and these facts are a matter of clinical concern and managerial introspection. The reasons for this may lie in the situational content of the publications and the mindset of the readers.
\end{abstract}

MJAFI 1997; 53: 122-126

KEYWORDS : Health planning; Health surveys; Length of stay; Morbidity.

$\mathbf{R}$ eports are meant to be read. The situation regarding the prestigious 'Report on the Health of the Armed Forces' is, however, depressing. Many are unaware of its very existence. It took considerable efforts to obtain a copy of the report pertaining to the year 1990, published in 1993 and received during 1994. The contents were startling in several respects. Even more surprising, however, was the disturbing fact that this remarkable document had escaped widespread attention and critical comment. An exercise was undertaken to analyze and critically evaluate the same.

Data were acquired from the 'Annual Report on the Health of the Army' for 1986 and 1987, and the 'Report on the Health of the Armed Forces' for 1989 and 1990 [1-4]. Certain parameters were selected to highlight significant longitudinal and cross-sectional trends. Data were tabulated and analyzed accordingly.

\section{Average Length of Stay in Hospital}

Average length of stay (ALS) in days in respect of selected diseases has been tabulated for the period 1986-1990 (Tables 1 and 2). Base year for mental disorders and common cold (Table 2) has been taken as 1982. Arithmetic mean was taken as the point of reference, and a swing of over 10 per cent on either side scored as 'erratic'. The lowest
ALS for a particular disease constituted the baseline, and any figure more than 20 per cent above this was classified 'high'. Wide and apparently random variations were seen in longitudinal as well as cross-sectional profiles. ALS for tuberculosis in serving personnel, for instance, varied between 106.6 days (during 1990) to 286.1 days (during 1988). From 223.9 days in 1989, ALS dropped to 106.6 during 1990; the latter figure is nearer to that for Military Nursing Service (MNS) officers (120.3 days) during 1986. Similar trends were observed for diabetes mellitus and heart disease (Table 1). The swings were even more violent with regard to neoplasms (2.4 days for MNS in 1987 to 40.4 for serving personnel in the same year, Table 1), common cold ( 3.7 days for naval officers' wives in 1989 to 34.8 for army Junior Commissioned Officers and Other Ranks' wives (JCO/OR wives) during 1987), pneumonia (3.7 days for naval officers' wives in 1989 to 180.8 for MNS in 1987), and bronchitis ( 5.8 days for naval officers' wives in 1990 to 53.1 days for Army Officers' wives during 1986). ALS for psychiatric patients (serving personnel) remained consistently high, but had come down from the 1982 level of 65.9 days. The corresponding figure for the MNS was a more reasonable 26.4 days (mean).

\section{Incidence of Psychiatric Illnesses}

Longitudinal trends of incidence of psychiatric

Senior Adviser (Psychiatry), Military Hospital Jodhpur - 342010 
TABLE 1

Year-wise length of stay for tuberculosis, diabetes, heart disease and neoplasm

\begin{tabular}{llrrrrrrrr}
\hline Disease & Patient group & 1986 & 1987 & 1988 & 1989 & 1990 & Mean & Swing & Level \\
\hline Tuberculosis & Serving personnel & 174.1 & 161.9 & 286.1 & 223.9 & 106.6 & 190.5 & Erratic & High \\
& MNS & 120.3 & 166.9 & - & - & - & 143.5 & Erratic & High \\
Diabetes mellitus & Serving personnel & 57.4 & 57.3 & 55.9 & 56.6 & 34.5 & 52.3 & Erratic & High \\
& MNS & 67.5 & 36.5 & - & - & - & 52.0 & Erratic & High \\
Heart disease & Serving personnel & 41.2 & 44.0 & 51.8 & 47.9 & 34.1 & 43.8 & Erratic & High \\
& MNS & 22.9 & 23.2 & - & - & - & 23.0 & Stable & Basal \\
Neoplasms & Serving personnel & 33.4 & 40.4 & 44.5 & 42.4 & 38.4 & 39.8 & Erratic & Basal \\
& MNS & 21.4 & 2.4 & - & - & - & 11.9 & Erratic & High \\
& & & & & & & & &
\end{tabular}

TABLE 2

Year-wise average length of stay for mental disorders, common cold, pneumonia and bronchitis

\begin{tabular}{|c|c|c|c|c|c|c|c|c|c|c|}
\hline Disease & Patient group & 1982 & 1986 & 1987 & 1988 & 1989 & 1990 & Mean & Swing & Level \\
\hline \multirow[t]{2}{*}{ Mental disorders } & Serving personnel & 65.9 & 47.3 & 55.1 & 47.6 & 51.4 & 51.0 & 50.5 & Stable & Basal \\
\hline & MNS & - & 26.4 & 26.4 & - & - & - & 26.4 & Stable & Basal \\
\hline \multirow[t]{8}{*}{ Common cold } & Serving personnel & 12.3 & 29.5 & 30.1 & 27.5 & 28.8 & 12.4 & 25.7 & Erratic & High \\
\hline & MNS & - & 8.0 & 25.3 & - & - & - & 16.6 & Erratic & High \\
\hline & Army officers' wives & - & 31.4 & 20.4 & - & 29.9 & 7.5 & 22.3 & Erratic & High \\
\hline & Army JCO/OR wives & - & 31.1 & 34.8 & - & 34.4 & 26.5 & 31.7 & Erratic & High \\
\hline & Army children & - & 21.7 & 27.6 & - & 16.3 & 8.0 & 18.4 & Erratic & High \\
\hline & Naval officers' wives & - & 一 & - & - & 3.7 & 6.0 & 4.8 & Erratic & Basal \\
\hline & Other naval wives & - & 一 & - & - & 9.0 & 7.5 & 8.3 & Stable & High \\
\hline & Naval children & - & - & - & - & 5.4 & 8.6 & 7.0 & Erratic & High \\
\hline \multirow[t]{8}{*}{ Preumonia } & Serving personnel & - & 21.5 & 22.6 & 20.4 & 21.5 & 25.5 & 22.3 & Erratic & High \\
\hline & MNS & - & 24.9 & 180.8 & 一 & - & - & 102.9 & Erratic & High \\
\hline & Army officers' wives & - & 38.6 & 35.8 & - & 40.0 & 39.0 & 38.4 & Stable & High \\
\hline & Army JCO/OR wives & - & 21.9 & 29.1 & - & 29.4 & 40.3 & 30.1 & Erratic & High \\
\hline & Army children & - & 8.7 & 7.0 & - & 7.9 & 27.1 & 12.7 & Erratic & High \\
\hline & Naval Officers' wives & - & - & - & 一 & 3.7 & 5.5 & 4.6 & Erratic & Highı \\
\hline & Other naval wives & - & - & - & - & 9.0 & 10.2 & 9.6 & Stable & High \\
\hline & Naval children & 一 & 一 & - & - & 9.0 & 7.6 & 8.3 & Stable & High \\
\hline \multirow[t]{8}{*}{ Bronchitis } & Serving personnel & - & 16.3 & 16.2 & 13.9 & 15.1 & 16.2 & 15.5 & Erratic & High \\
\hline & MNS & - & 16.9 & 13.5 & - & - & - & 15.2 & Stable & High \\
\hline & Army officers' wives & - & 53.1 & 23.7 & 一 & 24.6 & 18.2 & 29.9 & Erratic & High \\
\hline & Army JCO/OR wives & - & 23.2 & 24.8 & - & 25.5 & 21.9 & 23.9 & Stable & High \\
\hline & Army children & - & 8.0 & 8.6 & - & 10.3 & 20.6 & 11.8 & Erratic & High \\
\hline & Naval officers' wives & - & - & 一 & - & 11.0 & 5.8 & 8.4 & Erratic & High \\
\hline & Other naval wives & - & - & 一 & - & 6.6 & 6.6 & 6.6 & Stable & Basal \\
\hline & Naval children & - & - & - & - & 7.1 & 6.6 & 6.9 & Stable & Basal \\
\hline
\end{tabular}


illness showed a generally stable pattern over a fairly long span (1977-1990) except in the case of MNS officers where the wide fluctuations (2.05 to 9.64 per 1000) defy explanation (Table 3). Crosssectional dissonance of even greater magnitude was seen in the incidence of stress-related diseases (psychiatric diseases, ischemic heart disease (IHD), hypertension, peptic ulcer) among Army officers who were afflicted three to four times more often than JCOs/OR and Naval/Air Force officers (Table 4). This pattern become more pronounced when one tumed to IHD (Table 5). Even MNS officers fared better in respect of these two parameters.

TABLE 3

Category-wise incidence of psychiatric illness : 1977-1990 (Rate per 1000)

\begin{tabular}{lcccc}
\hline Year & Officers & JCOS/OR & MNS & $\begin{array}{c}\text { All Army } \\
\text { personnel }\end{array}$ \\
\hline 1977 & 3.73 & 3.34 & 9.64 & 3.39 \\
1978 & 3.44 & 3.19 & 4.83 & 3.21 \\
1979 & 3.49 & 3.24 & 7.16 & 3.26 \\
1980 & 3.61 & 3.62 & 3.88 & 3.62 \\
1981 & 2.83 & 3.05 & 4.46 & 3.04 \\
1982 & 3.61 & 2.73 & 3.77 & 2.76 \\
1983 & 3.49 & 2.66 & 4.48 & 2.70 \\
1984 & 3.55 & 2.58 & 9.35 & 2.62 \\
1985 & 3.33 & 2.47 & 3.24 & 2.50 \\
1986 & 3.96 & 2.50 & 2.05 & 2.54 \\
1987 & 3.52 & 2.09 & 6.30 & 2.14 \\
1988 & 4.13 & 2.33 & 6.12 & 2.39 \\
1989 & 3.92 & 2.66 & 3.63 & 2.70 \\
1990 & 3.49 & 2.44 & 2.53 & 2.47 \\
\hline
\end{tabular}

\section{TABLE 4}

Category-wise incidence of stress related diseastes : 1988-90 (Rate per 1000)

\begin{tabular}{llrrrr}
\hline Service & Category & 1988 & 1989 & 1990 & Mean \\
\hline Army & Officers & 19.01 & 23.34 & 21.03 & 21.13 \\
& MNS & 13.76 & 10.90 & 8.68 & 11.11 \\
& JCOs/OR & 5.80 & 6.40 & 5.66 & 5.95 \\
& Overall & 6.21 & 6.90 & 5.13 & 6.14 \\
Navy. & Officers & 6.45 & 5.89 & 5.37 & 5.90 \\
& Sailors & 5.03 & 4.66 & 5.02 & 4.90 \\
& Overall & 5.23 & 4.82 & 5.06 & 5.04 \\
Air Force & Officers & 7.26 & 7.40 & 7.44 & 7.37 \\
& Aimmen & 5.67 & 5.23 & 4.94 & 5.28 \\
& Overal & 5.81 & 5.40 & 5.12 & 5.44 \\
\hline
\end{tabular}

TABLE 5

Category-wise incidence of ischem ic beart diseases : $1988-$ 90 (Rate per 1000)

\begin{tabular}{llllll}
\hline Service & Category & 1988 & 1989 & 1990 & Mean \\
\hline Army & Officers & 7.30 & 9.71 & 9.40 & 8.80 \\
& MNS & 1.91 & 2.91 & 2.53 & 2.45 \\
& JCOs/OR & 0.80 & 0.83 & 0.66 & 0.76 \\
& Overall & 0.99 & 1.09 & 0.93 & 1.00 \\
Navy & Officers & 1.72 & 2.15 & 2.32 & 2.06 \\
& Sailors & 0.45 & 0.30 & 0.34 & 0.36 \\
& Overall & 0.63 & 0.55 & 0.60 & 0.59 \\
Air Force & Officers & 4.26 & 3.70 & 3.32 & 3.76 \\
& Airman & 1.15 & 1.25 & 1.14 & 0.28 \\
& Overall & 1.40 & 1.44 & 1.30 & 1.38 \\
\hline
\end{tabular}

Inter-Command variations in morbidity also struck a discordant note with the 'peaceful' Central Command showing highest incidence among officers as well as JCOs/OR (Table 6). In contrast Northem Command appeared to be the healthiest for officers despite its harsh terrain and climate.

\section{Discussion}

Annual reports on the health of the Armed Forces constitute an invaluable source of information relevant to clinical practice, health administration, and research. Few other organizations in the country offer such a rich feast of relevant information on a platter and it invariably evokes envy among civilian colleagues. The author has used these data with considerable benefit in earlier studies [5-7].

Armed Forces Medical Services are unique in having a specialist cadre trained mainly in one institution, the Armed Forces Medical College. Coupled with uniformly trained paramedical staff and a regimented clientele this should have resulted in an almost stable clinico-managerial parameter such as ALS. In the aforesaid context disparate longitudinal as well as cross-sectional trends cited earlier are (or should be) a matter of deep clinical concern and managerial introspection. Yet these appear to have passed virtually unnoticed. Violent variations in ALS from year to year, and in the same year between different categories of patients hospitalized for the same disease have failed to evoke critical comment or corrective action. Few appear to have noted the two and a half times 
TABLE 6

Hospital admission rates per 1000 by categories/Commands : 1982-87

\begin{tabular}{lrrrrrrr}
\hline Category/Comd & 1982 & 1983 & 1984 & 1985 & 1986 & 1987 & Mean \\
\hline Officers & & & & & & & \\
$\quad$ Southern & 228.81 & 303.02 & 231.10 & 214.69 & 221.28 & 218.75 & 236.28 \\
Eastern & 149.69 & 175.65 & 142.18 & 141.73 & 145.03 & 137.10 & 148.56 \\
Western & 139.45 & 140.53 & 140.19 & 113.39 & 119.03 & 123.07 & 129.28 \\
Central & 246.18 & 256.92 & 239.47 & 215.57 & 228.80 & 219.07 & 234.34 \\
$\quad$ Northern & 118.07 & 116.30 & 134.21 & 123.63 & 108.18 & 118.76 & 119.86 \\
JCOs/OR & & & & & & & \\
Southern & 161.42 & 167.97 & 168.20 & 161.68 & 159.31 & 150.63 & 161.50 \\
Eastern & 136.50 & 137.43 & 120.23 & 118.62 & 115.35 & 111.30 & 123.24 \\
Western & 106.52 & 111.85 & 119.81 & 105.12 & 91.71 & 84.11 & 103.19 \\
Central & 184.15 & 203.81 & 212.02 & 189.02 & 186.28 & 155.63 & 188.49 \\
Northern & 115.21 & 112.82 & 121.13 & 111.23 & 102.83 & 86.00 & 108.2 \\
\hline
\end{tabular}

increase in ALS for common cold cases between 1982 (12.3 days) and 1986-89 (mean 28.9), before declining equally inexplicably to 12.4 days in 1990. This clinical extravagance compares unfavourably with ALS less than 11 days at the Birla Heart Research Centre, Calcutta, which almost exclusively handles seriously ill patients. Even greater discordance between Army and Naval officers' wives (mean ALS 22.3 days versus 4.8 days), and other Amy and Naval wives (mean ALS 31.7 days and 8.3 days) hospitalized for the same problem (common cold) has also failed to produce any excitement. The scenario is repeated ad infinitum with regard to other ailments.

The situation in respect of stress diseases and IHD is even more distressing. Abnormally high vulnerability of Army officers, when compared to their counterparts in the Navy and the Air Force, has not lead to any wide-based prospective study to identify what may be highly specific additional risk factors in this large sub-group of serving personnel. Preventive measures can be planned and instituted only when authentic inputs are available. This must rank as one of the most tragic failures of the military medical fraternity.

Far more disturbing, however, is the inescapable inference that the invaluable information contained in the aforesaid Annual Reports has remained unread, uninterpreted, and unutilized. Even at the risk of being labelled platitudinous one is tempted to employ that well-worn cliche, 'starvation in the midst of plenty' to describe this situ- ation. We have deprived ourselves of a vital macro-input which could and should have played a seminal role in formulating pragmatic clinicomanagerial policies and prospective health planning to ensure optimal utilization of available resources. This is of immediate relevance in the context of virtually stagnant defence allocations and changing national priorities.

In this context is would be relevant to explore the mindset of the consumer audience - ourselves. It appears that we have failed to evolve beyond the ambit of narrowly - defined 'technical competence'. Unable to visualize the macro consequences of our micro level role, we have conveniently absolved ourselves of the responsibility for what is conveniently termed as a 'systems failure'. Honest introspection would, however, lead us to the inevitable conclusion that our individual failings get pooled, multiplied, and eventually magnified into a failure of the system. Vast and apparently irrational fluctuations in ALS are a direct consequence of clinical indolence and managerial ineptitude [7-9]. Responsibility rests squarely on treating clinicians, with the administrators being either unwilling or incapable of effective superintendence. The Annual Health Report mirrors our cumulative failings and foibles. By leaving it unread we are denying ourselves the benefit of a vital and incisive input. Senior Advisers and Commanding Officers would do well to use it as a frame of reference while monitoring and evaluating individual as well as organizational performance. 


\section{REFERENCES}

I. Annual Report on the Health of the Army 1986. Directorate General of Medical Services, Army Headquarters, New Delhi 1990.

2. Annual Report on the Health of the-Army 1987. Directorate General of Medical Services, Army Headquarters, New Delhi 1990.

3. Report on the Health of the Armed Forces 1989. Directorate General Armed Forces Medical Services, Ministry of Defence, Government of India, New Delhi 1992.

4. Report on the Health of the Armed Forces 1990. Directorate General Armed Forces Medical Services, Ministry of Defence, Government of India, New Delhi 1993.

5. Goel DS. Psychiatric morbidity among ASC drivers: prod- uct of socioeconomic stress? Medical Joumal Armed Forces India 1974; 31: 71-9.

6. Goel DS. Attempted suicide in the Armed Forces: a study of psychosocial and preventive aspects in an 'active' command. Indian Joumal of Psychiatry 1975; 17: 163-73.

7. Goel DS, Saldanha D. Brief hospitalization: preliminary report on the Chandigarh experience. Medical Joumal Armed Forces India 1992; 48: 27-34.

8. Goel DS, Saldanha D, Rathee SP. Changing patterns of mental morbidity: artefact of psychiatric policy? Medical Journal Armed Forces India 1991: 47: 275-9.

9. Goel DS. Caveat vendor: the mythology of medical classification. Combat Journal 1992; 19: 60-6. 